\title{
Práticas de Pesquisa em Educação no Brasil: lugares, dinâmicas e conflitos
}

\author{
Silvio Sánchez Gamboa \\ Faculdade de Educação \\ Universidade Estadual de Campinas
}

Resumo: O texto discute as condições da produção da pesquisa científica em educação. Aborda a evolução da pesquisa nas últimas décadas e as conseqüências da sua localização restrita aos programas de pósgraduação. Destaca questões relativas aos limites e possibilidades dos diversos enfoques epistemológicos da pesquisa e seus desdobramentos para a pesquisa em Educação Ambiental. Conclui apontando novas condições da produção do conhecimento: articulando a extensão, ensino e a pesquisa; graduação e pós-graduação; e sinalizando as vantagens da pesquisa interdisciplinar, organizada em linhas de pesquisa e também em redes e intercâmbio nacional e internacional.

Palavras-chave: Condições da Produção do Conhecimento. Epistemologia da Pesquisa Educacional. Tendências da Pesquisa Educacional.

Abstract: The text argues the conditions of the production of scientific research in education. It approaches the evolution of such research in the last decades and the consequences of its restricted localization to the postgraduate programs. It detaches questions related to the limits and possibilities of the diverse epistemological approaches of research and its unfoldings for the research in Environmental Education. It concludes pointing new conditions of knowledge production: articulating extension, education and research; graduation and postgraduation; and signaling the advantages of interdisciplinary research, organized in lines of research as well as in networks and national and international interchange.

Keywords: Conditions of Knowledge Production. Epistemology of Educational Research. Trends of Educational Research. 


\section{Introdução}

Por ocasião do III Encontro de Pesquisa em Educação Ambiental, foram retomadas as questões epistemológicas que permeiam a pesquisa em educação em geral e suas relações necessárias com a pesquisa ambiental. Nesse contexto, apresentamos algumas considerações sobre as práticas da pesquisa educacional, delineando alguns traços do seu desenvolvimento restrito aos cursos de pós-graduação, determinando limites e possibilidades para a pesquisa em Educação Ambiental. O presente texto que resume essa apresentação foi organizado em três partes. $\mathrm{Na}$ primeira, problematizamos algumas dificuldades, indicando os conflitos da prática da pesquisa com as teorias, os lugares restritos da pesquisa educacional e os limites das diversas dinâmicas da produção científica que se estabeleceram no seio dos programas de pós-graduação. Na segunda, delineamos uma agenda dos desafios, das novas práxis da pesquisa e novos lugares no contexto da universidade. Por fim, são apresentadas algumas conclusões relativas aos desafios da Educação Ambiental.

\section{Roteiro das dificuldades}

Nesta primeira parte, retomamos alguns dos principais problemas da pesquisa em educação relativos à sua prática e aos seus conflitos com as teorias científicas e pedagógicas, às restrições quando seu desenvolvimento se limita aos programas de pósgraduação e à influência de modelos epistemológicos que delimitam o seu potencial. Vejamos de forma sucinta essas dificuldades.

1.1. A prática da pesquisa em educação se depara de forma conflitante com as teorias científicas que permitem seus recortes, possibilitam suas análises e suas interpretações. A preocupação com as questões teóricas, metodológicas e epistemológicas hoje ganha novos contornos. A pesquisa educacional está ultrapassando a fase de "ciência aplicada" caracterizada pela apropriação simples de métodos e referências desenvolvidas em outras áreas - por exemplo, as ciências da educação "tomaram emprestado" da Sociologia, da Psicologia, da Economia, da Filosofia, da História, etc. seus métodos 
e mesmo sua linguagem. Hoje, na busca de um estatuto próprio, recebe o socorro dessas ciências, sofrendo as flutuações do denominado "colonialismo epistemológico" dessas "ciências-mães". A Educação tornou-se um campo colonizado, onde são aplicados os métodos e as teorias das "ciências-mães", denominadas na sua versão aplicada de Psicologia da Aprendizagem, Psicologia da Educação, Sociologia da Educação, História da Educação, Biologia da educação, etc.

Essas flutuações, tal como afirma Orlandi (1983), referindose à relação do saber pedagógico com as ciências que lhe prestam socorro, como a Psicologia, a Sociologia e a Economia, significam "a adesão pré-crítica do saber pedagógico a estruturas conceituais limitadas pelos interesses das várias teorizações e práticas humanas centradas em seus objetos específicos" (p. 24). Elas expressam o circuito simples dos saberes científicos, organizados em disciplinas que toma como ponto de partida e ponto de chegada, as teorias sociológicas, psicológicas, administrativas, e não a Educação, que funciona como campo de passagem ou faz o papel de pretexto. Esses saberes já constituídos nas várias ciências são aplicados aos fenômenos da Educação na tentativa de explicá-los e retornam à matriz disciplinar confirmando suas hipóteses, num circuito em que os fenômenos da Educação são pontos de passagem das elaborações científicas, caracterizando, assim, um processo de "colonialismo epistemológico" sobre um campo aberto e "sem dono" ou com muitos donos.

A pesquisa educacional, por outro lado, também corre o risco do predomínio da prática, se distanciando das teorias. Uma nova flutuação conhecida como pragmatismo. A prática torna-se ponto de partida e de chegada, e a teoria perde importância (ponto de passagem) quando tomada apenas como um arrazoado de justificativas da prática. Aparecem os levantamentos "Surveys", estudos de caso, "os olhares para a prática". Ou na forma contemporânea do neopragmatismo, quando a prática ganha destaque, mas sem considerar a mediação da teoria (recuo da teoria), e se manifesta em estratégias como a do "professor reflexivo" e as "aventuras dos métodos" (cf. MORAES, 2001 e 2002).

A superação da fase de "ciências aplicadas" das flutuações pragmatistas e do "colonialismo epistemológico" exige reverter o circuito do conhecimento. Toma-se, então, como ponto de partida e 
de chegada, a Educação e, como instrumental explicativo ou compreensivo, a contribuição teórica de diversas disciplinas.

Isso implica a articulação de um campo interdisciplinar que tem como eixo a natureza e a especificidade da Educação, que articula a contribuição das várias teorias científicas e elabora explicações e compreensões mais ricas e complexas na medida em que tece, em torno de fenômenos concretos, interpretações, articuladas pelo eixo central, da prática pedagógica ou ação educativa Tais asserções remetem-nos a outras questões, como a especificidade dos novos campos epistemológicos e a natureza da Educação.

Nessa perspectiva, o circuito do conhecimento parte do fenômeno da educação e as teorias científicas oriundas das diversas ciências, entre elas, a Psicologia, a Sociologia, a Economia, as ciências biológicas, etc. contribuem com suas hipóteses, teses e abstrações na explicação e compreensão desses fenômenos. Dessa forma, são convidadas a oferecer seus ricos elementos explicativos para a elaboração de um conhecimento do fenômeno educacional. O circuito continua na volta aos fenômenos, explicando-os, compreendendo-os e sugerindo sua modificação e aprimoramento. Cria-se um movimento cognitivo dos fenômenos para os fenômenos, gerando explicações e compreensões que motivam e racionalizam a ação transformadora e articulam estreitamente a prática-teoria-prática.

Nessa virada que as ciências da Educação estão realizando, tomando a ação e a prática como eixo central, as teorias, as sistematizações, as abstrações ganham um sentido concreto, na medida em que se convalidam pertinentes sob os critérios da práxis transformadora, e estes, por sua vez, criam uma tensão crítica sobre a prática, produzindo novos critérios de ação transformadora.

Nessa linha de raciocínio, a Educação, assim como outros novos campos epistemológicos, cujos objetos de pesquisa são a ação, a prática e a práxis, respeitando suas especificidades, desafiam as atuais classificações das ciências, divididas em básicas e aplicadas, naturais, humanas, etc. Desse modo, dimensionam-se como campos epistemológicos diferentes e invalidam as classificações anteriores. Torna-se necessário procurar uma nova categoria de ciência para localizar as especificidades desses novos campos que têm a ação e a prática como ponto de partida e de chegada da produção de conhecimentos. A definição de ciências práticas ou da ação parece oferecer alguma segurança. Dessa forma, a Educação perfila-se como 
uma ciência com relativa especificidade, por ter um objeto próprio: a prática pedagógica e a ação educativa.

Nesse caso, como em outros em que a prática e a ação são o alvo da elaboração científica, é possível, segundo Schmied-Kowarzik (1988), a superação da tradicional divisão das ciências entre básicas e aplicadas, criando-se uma nova categoria para as novas ciências tais como a Pedagogia, a Política e a Ética ${ }^{1}$. Na sua especificidade, a Pedagogia, por exemplo, como teoria da educação, pretende não apenas compreender a prática educativa, mas voltar-se sobre essa prática, sinalizando seu aprimoramento. É uma ciência da e para a ação educativa e, como tal, busca sistematizar a reflexão crítica dos processos educativos. Nesse sentido, reclama para si o estatuto de ciência, portanto, um espaço privilegiado entre as Ciências da Educação.

A definição da Educação como uma das ciências da prática e da ação não é apenas por ter como ponto de partida e de chegada a prática, mas, como afirma Saviani, por se tratar da própria natureza da educação, tida como ação social ou como trabalho. Trabalho cujo valor intrínseco está no processo e não no produto. Trabalho, definido pelo autor, como sendo não material, tendo em vista que o trabalho material gera um produto a ser consumido depois do processo de produção. Na educação, caracterizada como trabalho não material, o produto não se separa do ato de produzir, isto é, quando "O ato de produzir e o ato de consumo se imbricam" (1991, p.20). No caso do trabalho não material, o processo, a ação e a prática se tornam essenciais. A educação acontece no mesmo ato educativo ou na ação pedagógica.

O mesmo acontece com a classificação em ciências naturais e humanas que se inviabiliza quando a compreensão da natureza humana implica a profunda articulação entre a natureza biofísica e a natureza sociocultural transmitida de uma geração para outra. A educação torna-se um processo de produção social da humanidade em cada homem a partir da sua natureza biofísica. A natureza humana produzida socialmente constitui algo como uma segunda natureza, com base na natureza físico-biológica. A educação é um

${ }^{1}$ Ciências que têm como objeto os atos: o ato pedagógico, o ato político, o ato moral. Nessa nova divisão das ciências, a Pedagogia, a Política e a Ética se aproximam, na medida em que os atos pedagógicos também são atos políticos e atos morais e, em conseqüência, os atos políticos são também atos morais e pedagógicos, etc. 
trabalho não material necessário à constituição humana do homem. Produz a natureza humana que não está pronta na natureza biofísica.

Portanto, o que não é garantido pela natureza tem que ser produzido historicamente pelo homem; e aí se incluem os próprios homens. Podemos, pois dizer que a natureza humana não é dada ao homem, mas é por ele produzida sobre a base da natureza biofísica. Conseqüentemente, o trabalho educativo é o ato de produzir, direta e intencionalmente, em cada indivíduo singular, a humanidade que é produzida histórica e coletivamente pelo conjunto dos homens (SAVIANI, 1991, p. 21).

A natureza da Educação está no trabalho não material, cujo produto se dá no mesmo processo da atividade, do fazer, da realização do ato educativo, atividades e processos que, desenvolvendo a natureza biofísica do homem, desenvolvem fundamentalmente sua natureza humana. Atos e processos complexos nos quais é impossível separar as "duas naturezas" porque se imbricam mutuamente, constituindo uma unidade concreta na ação humana direta e intencional (trabalho) que transforma a natureza biofísica do homem. Nesse sentido, a educação não é objeto exclusivo nem das ciências naturais ou biológicas, nem das ciências humanas e sociais. Daí o seu caráter interdisciplinar centralizado nas práticas pedagógicas e nas ações educativas.

1.2. Os lugares restritos da pesquisa educacional ${ }^{2}$. Outra dificuldade, além da relação teoria e prática, que afeta o desenvolvimento da pesquisa educacional refere-se à tardia vinculação da pesquisa na universidade brasileira ${ }^{3}$. A pesquisa em

2 Esses registros sobre o desenvolvimento recente da pós-graduação em Educação já foram trabalhados em textos anteriores num outro contexto de discussão (Ver SANCHEZ GAMBOA, 2003 e 2005.)

3 A universidade no Brasil surgiu tardiamente, com relação aos demais países da América Latina, que criaram suas primeiras universidades na época da colônia (1624 a Universidade de São Domingos). Apenas em 1823 foram criados os primeiros cursos de ensino superior (Cursos jurídicos de Olinda e São Paulo). Os primórdios da pesquisa se localizam em 1890 na Faculdade de Engenharia de Porto Alegre e no Instituto Agronômico de Campinas. Em 1920, cria-se a Universidade de Rio de Janeiro, em 1934, a Universidade de São Paulo, por aglomerado de faculdades, voltadas para o ensino profissionalizante, mas sem a pesquisa, mesmo que a Reforma Campos (1931) já fale da necessidade dela na universidade. Somente em 1968, por ocasião da Reforma da 
educação começou a ser desenvolvida, também, de forma restrita e limitada. Gouveia (1971), numa periodização da pesquisa desenvolvida no Brasil a partir dos anos 40 até 1971, aponta esses limites. Ela classifica a evolução da pesquisa educacional em três períodos.

1. Período que abrange a década de 40 e metade da década de 50. Teve início com a criação do INEP (Instituto Nacional de Estudos e Pesquisas Pedagógicas) e é marcado pelo predomínio dos temas psicopedagógicos que desenvolvem trabalhos de psicologia aplicada, estudos e testes de inteligência, de aptidões e de escolaridade.

2. Período que abrange a segunda metade da década de 50 e parte da década de 60. Teve início com a criação do Centro Brasileiro de Pesquisa Educacional (CBPE) e dos Centros Regionais de Pesquisa (CRPE). Nessa época, predominaram os temas e estudos sociológicos que tratam da organização social da escola e das relações entre educação e sociedade.

3. O terceiro período inicia-se em 1964; teve o predomínio temático dos estudos de economia da educação e aparecem trabalhos sobre a educação como investimento e como formação de recursos humanos.

4. O quarto período vem a partir de 1971, com o surgimento dos primeiros programas de pós-graduação, o reaparecimento dos estudos psicopedagógicos com preocupação técnica (avaliação, currículo, metodologia do ensino, programas etc.) e o aparecimento de estudos mais amplos com relação à política educacional. Esse período, segundo Cunha (1991), também se caracteriza pela dispersão temática (ponto de inflexão), pelo conflito entre a Educação e as educações, pelo colonialismo epistemológico e pelo processo de composição inorgânica das denominadas áreas de concentração (Pareceres 977/65 e 77/69 do CFE).

Universidade, é que passam a existir condições para o desenvolvimento da pesquisa, mas restrita aos cursos de pós-graduação (Pareceres 977/65 e 77/69 do CFE). 
5. O quinto período (a partir do final da década dos anos 80) se constitui a partir da crise do modelo de áreas de concentração e o surgimento das linhas de pesquisa. Nesse período, a pesquisa ganha centralidade e os problemas complexos da educação ganham destaque como ponto de partida e de congruência da pesquisa (composição orgânica multidisciplinar) ${ }^{4}$. Entretanto, constata-se a difícil ruptura com a concepção analítica da ciência e com a organização do conhecimento por áreas e dos saberes acadêmicos em disciplinas. Vejamos alguns detalhes dessas ultimas fases, uma vez que nelas surgem os conflitos e as possibilidades da pesquisa em Educação Ambiental.

No final dos anos 80 e começo dos 90, a maior parte dos Programas de Pós-Graduação em Educação enfrentava uma crise gerada pelo modelo de áreas de concentração. Tal modelo exigia numerosas disciplinas obrigatórias, limitava ainda as disciplinas eletivas a áreas de domínio conexo e postergava a realização das dissertações e das teses para a fase final do curso, quando o tempo de integralização curricular do aluno estava se esgotando.

As iniciativas para mudar essa estrutura centralizada nas áreas de concentração têm em comum: a) a prioridade dada à pesquisa e a diminuição do valor dado às disciplinas obrigatórias; b) a organização de grupos de estudos e pesquisas, que alteraram as condições institucionais da produção de dissertações e teses e c) a exigência no processo de seleção para os candidatos apresentarem projetos ajustados às linhas de pesquisa dos programas.

Alguns registros sobre essas iniciativas podem ser entendidos como uma "virada" da centralidade do ensino para a pesquisa. A centralidade no ensino representada pelas áreas de concentração e disciplinas obrigatórias deu espaço para um novo

${ }^{4}$ Essa discussão sobre a mudança de eixo dos Cursos de Pós-Graduação das áreas de concentração para linhas de pesquisas ou núcleos temáticos pode ser acompanhada nos debates da Associação Nacional de Pós-Graduação e Pesquisa em Educação -ANPED- a partir de 1988 e registrada no documento Avaliação e Perspectivas (1993), especialmente nos textos de Fávero e Warde. Discussões sobre essa tendência também podem ser encontradas na publicação do Foro Paulista de Pós-Graduação (BICUDO et al., 1993; SEVERINO e FAZENDA, 2001 e SAVIANI, 1999 e 2002). 
eixo, a pesquisa, representada na exigência dos projetos no processo de seleção e na formação de linhas e grupos de pesquisa.

Em 1987, o documento da ANPED resultante da Reunião de Avaliação da CAPES, referente ao período 85/86, indicava que alguns cursos dos 34 existentes até então $(27$ mestrados e 07 doutorados) estavam inovando no elenco de disciplinas, incluindo espaços para a preparação ou discussão de projetos de dissertação: "Esta tendência deve ser valorizada e intensificada, uma vez que pode contribuir para alcançar a meta de produção de dissertações com mais qualidade e em prazo mais reduzido, bem como de forma mais integrada" (ANPED, 1987, p. 60). O documento em referência também indicava o conflito entre os projetos isolados, no contexto das áreas temáticas, e os projetos articulados, vinculados às linhas de pesquisa:

A questão linhas versus projetos de pesquisa ainda permanece. Alguns programas tendem a adotar linhas de pesquisa, predominando nesses casos uma produção regular. Tal tendência parece estar mais presente nos programas melhor consolidados ou de melhor padrão (ANPED, 1987, p. 60).

Os conflitos e as mudanças da pós-graduação no final da década dos anos 80 se referem basicamente às condições institucionais da produção da pesquisa, assim interpretadas por Warde:

a) o lugar subordinado da pesquisa em relação ao ensino, cuja versão mais atualizada vem provocando a crítica às "áreas de concentração" em contraposição às "linhas de pesquisa" e, num período mais recente, ao caráter formalista dessas linhas mesmas (...) b) as causas da subordinação da pesquisa ao ensino e suas seqüelas: a falta de condição nas universidades; ausência de tradição de pesquisa nos meios educacionais, em geral e nas universidades, em particular; baixo respaldo das agências de fomento; ritualização e burocratização dos cursos ou (...) instalação da "lógica credencialista"(...) (1990, p. 69) .

5 Tanto o interesse pela titulação acadêmica dos próprios docentes das universidades como a dedicação do tempo que privilegia a realização de créditos disciplinares em relação à dissertação são indicadores da subordinação da pesquisa a outros interesses distantes da produção do conhecimento, trazendo assim outros fatores desagregadores de um projeto orgânico. 
Warde se apóia em Kuenzer (1986) e Gatti (1987) para denunciar a subordinação e as precárias condições do desenvolvimento da pesquisa, destacando, entre elas: as contribuições negativas das áreas de concentração que alimentam a descontinuidade, a dispersão e desarticulação das pesquisas e a indefinição do mestrado entre formar professores ou pesquisadores, além do esquizofrênico distanciamento entre graduação e pós-graduação e o vínculo orgânico da pós-graduação com os departamentos, fatores que não só impediam a assimilação dos possíveis avanços realizados nas pesquisas localizadas unicamente na pós-graduação e distantes das práticas docentes, como também acarretavam uma total falta de autonomia dos cursos de pós-graduação em relação aos departamentos. Warde também destaca algumas soluções propostas pela literatura da época:

Dentre as soluções ou propostas destacam-se: (...) a mudança na estrutura e na dinâmica dos cursos, de forma que a pesquisa passe a ocupar o lugar central e o ensino um lugar subordinado (essa inversão não é destacada na maioria dos textos, e quando aparece, não são extraídas todas as conseqüências do privilegiamento da pesquisa sobre o ensino). Essa última proposta tem ganho o seguinte enunciado: extinção das "áreas de concentração" e centralização nas pesquisas, após a desformalização das "linhas" que as configuram (WARDE, 1990, p. 69).

Entretanto, frisa a autora, o mal maior da pós não está nas "áreas de concentração" e na sua relação com as "linhas de pesquisa", mas na sua interlocução social, nos destinatários ou depositários das empreitadas das pesquisas, nas concepções de pesquisa, nos quadros que pretende formar e nos espaços sociais e institucionais para os quais estão preparando esses quadros.

A discussão sobre os rumos da pós-graduação e da pesquisa nela produzida se faz mais intensa no começo dos anos 90: Cunha (1991) atribui ao Parecer 977/65 do CFE o arranjo para juntar um corpo docente diverso, prevendo a existência das áreas de concentração e das disciplinas de domínio conexo, precedidas por um grupo de disciplinas básicas, trazendo como elemento negativo o processo de composição inorgânica. A heterogeneidade dos professores que ofereciam introduções gerais sobre diversas 
disciplinas, somada à também heterogeneidade dos estudantes, criou uma inorganicidade circular que afetou o nível acadêmico da pós-graduação e a qualidade da pesquisa por abordarem temas muitos diversos de forma improvisada, ajustando interesses conflitantes e justificando cargas horárias das denominadas disciplinas obrigatórias, mas sem conseguir tempo para a elaboração dos textos terminais das dissertações e teses.

Não é possível que cada programa - menos ainda que cada orientador possa dar conta de todos os temas. Parece que existe um ponto de vista que serve para tratar de qualquer problema. Ao invés de o problema guiar a pesquisa, é o ponto de vista que o faz. É uma espécie de fetichismo que faz o caminho prevalecer sobre o destino. Não é de admirar, assim, que demore tanto tempo para que grande número de teses e dissertações sejam apresentadas (CUNHA, 1991, p. 43).

Cunha propõe a inflexão da pós-graduação oferecendo um programa de ensino orgânico, em nível de cursos de especialização, para atender as demandas de capacitação de professores, delimitando o foco dos mestrados em busca de uma maior especificidade dos programas, abandonando as pretensões generalistas, acabando com as áreas de concentração. Dessa forma, cada programa escolheria uma "linha" específica que permitiria a reunião de esforços, tanto em termos de juntar bibliografias, equipamentos, laboratórios, alunos motivados quanto em termos de interação, de intercâmbio com professores estrangeiros e do desenvolvimento de pesquisas associadas a organismos internacionais.

Outro indicador do debate em torno da reformulação da pós-graduação aparece na Reunião Técnica Nacional de Coordenadores de Pós-Graduação realizada na UNICAMP em abril de 1991, que destaca entre suas conclusões a necessidade de uma política de pós-graduação e pesquisa em educação da ANPED.

Para a formulação de tal proposta, serão tomados como parâmetros:

- a pesquisa científica enquanto modo de produção do conhecimento, como eixo condutor dos programas/cursos de pós-graduação stricto sensu;

- a relevância da pesquisa básica, em especial na área das Ciências Humanas e Sociais, para a produção do conhecimento educacional; 
- a articulação entre as atividades de pesquisa, orientação e ensino, na produção e socialização do conhecimento científico, tendo como base dessas atividades, preferencialmente, o trabalho coletivo interdisciplinar e interinstitucional (Cadernos ANPED No 3, 1991, p. 49).

No balanço sobre a pós-graduação do período 1982-1991, organizado pela ANPED (1993), o texto de Fávero destaca no estudo sobre a trajetória da pós-graduação a mudança que vem ocorrendo nesse período e que se inicia com o questionamento e a superação das áreas de concentração por meio da definição dos eixos temáticos que coloca a pesquisa como fulcro da pósgraduação e que gera mudanças significativas nos cursos. Segundo Fávero, todos esses esforços de reestruturação são justificados, basicamente, por três princípios: flexibilidade curricular, interdisciplinaridade e integração ensino-pesquisa. A flexibilidade se refere à supressão das disciplinas obrigatórias e introdução de "atividades programadas". A interdisciplinaridade se refere à possibilidade de integração de profissionais de várias áreas trabalhando num projeto comum, à criação de núcleos interdisciplinares, assumindo projetos amplos e superando a estreiteza dos departamentos, ao pluralismo teórico-metodológico do corpo docente e à formação de grupos de trabalho (GTs) no interior da ANPED. A integração ensino-pesquisa se refere à superação de dois tempos descontínuos do mestrado, o momento dos créditos e o momento da dissertação. Os mecanismos dessa superação estariam na formação de grupos de pesquisa, na inclusão dos currículos nos seminários de pesquisa e na orientação coletiva nos grupos de pesquisa.

O texto de Fávero aponta como pontos críticos nas propostas de reestruturação a utilização de designações como área, eixos, linhas como sinônimos sem um critério valorativo e sem a discussão sobre o enfoque teórico-metodológico envolvido. Citando documentos da reformulação do IESAE da FGV, apresenta a oposição entre área de concentração e núcleo temático.

As áreas de concentração traduzem ênfase quase que exclusiva no ensino e centram-se no pressuposto de conteúdos já estruturados a serem transmitidos (...) epistemologicamente, as áreas de concentração centram-se na divisão apriorística do conhecimento, acarretando uma fragmentação arbitrária e às vezes imobilizadora do mesmo, não 
permitindo equacionar os verdadeiros problemas educacionais (...). Os núcleos temáticos partem da idéia de problematização e de processo de construção do conhecimento, bem como de uma organização dinâmica do mesmo, com vistas a sua sistematização e comunicação (FÁVERO, 1993, p. 42).

A linha de pesquisa tem várias interpretações, mas o autor destaca a compreensão de estar "constituída de um projeto de investigação, ou como um programa que envolva vários projetos, elaborado e desenvolvido por um grupo de professores e alunos de graduação e pós-graduação, derivado daí a nomenclatura grupo de pesquisa" (1993, p. 43). Também é entendida como projeto que ajuda a identificar o programa ou a definir a sua vocação, e, sobretudo, indica o compromisso com os grandes problemas da educação brasileira.

O Foro Paulista de Pós-graduação vem discutindo desde seus primeiros encontros (1992) o conflito da estrutura departamental e os programas de pós-graduação e "a discussão em torno de núcleos temáticos, linhas de pesquisa ou área de concentração" (SILVA, 2001, p. 23) ${ }^{6}$.

Em 1994, o debate sobre os processos de reestruturação dos programas continua, apontando tanto dificuldades na criação das linhas de pesquisa como possibilidades na perspectiva da produção interdisciplinar. Os programas de pós-graduação reagem "à idéia de trabalhar com linhas de pesquisa e núcleos temáticos, deixando de lado a idéia de trabalhar com áreas de concentração" (SILVA, 2001, p. 29), mas também sinalizam uma estrutura definida em torno dos núcleos temáticos. No caso de Supervisão e Currículo, "o programa trabalha com a interdisciplinaridade para desconstruir as áreas de concentração e criar núcleos de pesquisa e, conseqüentemente, a produção do conhecimento" (SILVA, 2001, p. 30).

Essas iniciativas indicam, além do esgotamento do modelo de áreas de concentração, implantado com base no Parecer CFE $977 / 65$, e da sua substituição por núcleos de pesquisa, uma mudança na concepção das condições de produção do

${ }^{6}$ O Foro Paulista de Pós-Graduação vem funcionando desde junho de 1992, com base no grupo de trabalho sobre pós-graduação organizado no I Congresso Paulista de Formação de Professores (Águas de São Pedro 1990). 
conhecimento. A ênfase dada ao ensino de pós-graduação, que obrigava os alunos a cursar disciplinas com conteúdos obrigatórios, é mudada para os projetos de pesquisa, de tal maneira que esses conteúdos ganham importância na medida em que oferecem subsídios para o desenvolvimento dos referidos projetos. A forma solitária da produção, ritualizada na orientação individual, é substituída pela dinâmica dos grupos de pesquisa.

De acordo com Severino (2001), justifica-se a mudança no compromisso da pós-graduação com a construção do conhecimento: "Portanto, deve ser lugar de pesquisa. Deve constituir-se como centro de pesquisa, onde se produz conhecimento mediante sua construção sistemática e permanente" (p.55). Essa nova perspectiva de pós-graduação voltada para a pesquisa também implica uma outra concepção de produção científica.

A concepção de conhecimento vinculada ao domínio de saberes acadêmicos e científicos, supostamente assimilados nas disciplinas obrigatórias, é revertida quando pretende se colocar como prioridade, a problemática traçada nos projetos de pesquisa. E ainda, essa mudança implica a pretensão de superar a concepção analítica da ciência, centralizada em conhecimentos especializados sobre fatores específicos de um fenômeno ou objeto e apoiada na divisão dos saberes em disciplinas e áreas de conhecimento (áreas de concentração), por uma perspectiva "multidisciplinar" a ser desenvolvida pelos grupos e as linhas de pesquisa.

As linhas de pesquisa, nessa perspectiva, referem-se fundamentalmente a campos de estudos aprofundados em torno de problemas que agrupam interesses comuns de investigadores oriundos de diversos campos do saber e de tradições científicas diferentes. O termo pesquisa indica o estudo de problemas, problematização da realidade, qualificação de questões, a dinâmica do conhecimento em torno de perguntas geradoras e a busca e construção de respostas científicas para os problemas abordados. A opção pelo eixo curricular da pesquisa significa priorizar, na agenda, a produção de conhecimentos sobre os problemas da realidade educacional com um tratamento crítico dos saberes acadêmicos e científicos acumulados nos conteúdos das, assim denominadas, disciplinas obrigatórias e de domínio conexo. Nesse sentido, os conceitos de linhas e grupos passam a ser privilegiados, 
e termos como áreas de concentração ou núcleos temáticos perdem relevância, ou são utilizados de forma imprópria ${ }^{7}$.

As linhas e grupos de pesquisa não podem ser entendidos como categorias estanques, ou subcategorias temáticas das antigas áreas de concentração. $O$ sentido da mudança, no âmbito de algumas associações nacionais como a ANPED (Associação Nacional de Pós-Graduação e Pesquisa em Educação), aponta para a compreensão das linhas e grupos de pesquisa como eixos que articulam interesses de diversos pesquisadores, propiciando $\mathrm{O}$ trabalho interdisciplinar, a contribuição e o concurso de diversas visões, diferentes abordagens teórico-metodológicas e o concurso de diversas tradições epistemológicas. Desdobra-se dessa compreensão a possibilidade de integrar num mesmo grupo um corpo de pesquisadores pertencentes a diversos departamentos de uma mesma unidade acadêmica, ou mesmo de outras unidades, em torno de um problema ou grupo de problemas cuja complexidade exige a contribuição do trabalho grupal e o domínio de diversas abordagens teórico-metodológicas.

Em síntese, a recuperação de alguns tópicos da história do Programas de Pós-Graduação relativos às mudanças de áreas de concentração para linhas de pesquisa nos permite ponderar alguns pontos polêmicos, tais como o progressivo abandono do conceito de "área de concentração" (Pareceres 977/65 e 77/69 do CFE), devido à conotação relacionada com a ênfase no ensino, na transmissão dos saberes acadêmicos científicos e de conteúdos já estruturados (disciplinas obrigatórias e de domínio conexo). Essa ênfase na divisão disciplinar e nos saberes já elaborados relegava a um segundo plano a pesquisa, a interdisciplinaridade e a produção do conhecimento voltada para os problemas da educação brasileira. A reestruturação em torno de núcleos de pesquisa ou núcleos temáticos significava uma nova perspectiva. A adoção de formas de orientação coletiva, seja como atividades orientadas em torno de um mesmo orientador, seja como atividades programadas de pesquisa (APP), bem como a organização de grupos, concentrando

7 O conceito tema sugere organização bibliográfica, classificação de arquivos, quadro de referências, sistematização de saberes elaborados. Pesquisam-se problemas e não propriamente temas. As tematizações podem ser o resultado de pesquisas ou maneiras de organizar os produtos das investigações. As problematizações criam a tensão da busca e os desafios que incentivam a construção do conhecimento. 
esforços e sistematizando o conhecimento produzido, significava novas condições da produção que tomava, como eixo central, a busca de respostas (novos conhecimentos) para os problemas da educação brasileira.

\section{As novas dinâmicas e lugares ampliados da produção do conhecimento}

2.1. Os tópicos apontados acima sugerem que a pesquisa educacional deverá desenvolver formas de superação da segmentação dos saberes em disciplinas e áreas de concentração e dos paradigmas analíticos (da simplicidade) que separam os objetos ou fenômenos de seus contextos, seus entornos, seus ambientes, das condições nas quais se originam e se desenvolvem (lugares "ecos" e tempos "cronos"). Tais abordagens que negam a ecologia e a historicidade dos fenômenos se amparam na divisão dos saberes científicos e na sua organização por disciplinas. A construção de paradigmas da complexidade que problematizam os fenômenos nos seus contextos e na sua evolução histórica exige abordagens histórico-compreensivas, atreladas a uma visão ampla e global da realidade, possível de ser constituída por meio de uma perspectiva interdisciplinar. Nas condições concretas da pós-graduação, essa construção é possível com a consolidação dos grupos e linhas de pesquisa, que na sua forma mais desenvolvida constituem redes interinstitucionais de pesquisa em nível nacional e internacional. Entretanto, todas essas dinâmicas ganham firmeza e rigor epistemológico e metodológico quando a pesquisa se centraliza nos problemas complexos da sociedade e da educação.

\subsection{Os problemas como eixos articuladores dessas dinâmicas}

Os problemas têm sua origem no mundo da necessidade, a necessidade de encontrar respostas para as indagações sobre os mistérios da natureza, sobre a experiência histórica do homem e a sua relação com essa natureza, necessidades gritantes e prementes de entender, entre outros, os conflitos que colocam em permanente risco a sobrevivência do homem e das demais espécies, de compreender e reverter os processos que levaram à degradação ambiental, à destruição da diversidade biológica e cultural e à 
deterioração dos recursos naturais e da qualidade de vida. Necessidade de conhecer a experiência cotidiana, a condição humana e os sentidos das práticas sociais. A essência do problema é a necessidade humana. Necessidade que responde a interesses concretos dos indivíduos e grupos sociais, que correspondem a diversas fases de desenvolvimento da humanidade e que, por isso, têm uma determinação histórica. Necessidades que ganham dimensões e intensidade de acordo com as condições de espaço (sítios, lugares) e de tempo (épocas, idades, fases de evolução) e que geram movimentos (insatisfações, motivações, buscas, ações, lutas, conquistas, transformações) em cada indivíduo em particular e na sociedade em geral.

Os problemas se dimensionam tanto objetivamente, quando expressam, de forma concreta, necessidades e interesses concretos, situados em espaços, tempos específicos, quanto subjetivamente, quando se manifestam por meio de insatisfações, desconforto, busca e quando os sujeitos que suportam esse problema têm consciência dessas necessidades. Dependendo dessas condições (objetivas e subjetivas), o problema ganha patamares de maturidade e de superação quando a necessidade se impõe objetivamente e é assumida subjetivamente (cf. SAVIANI, 1980).

Pelo acima exposto, o problema se comporta como um fenômeno complexo. Os fenômenos complexos, ao mesmo tempo em que se manifestam, se revelam, apresentando sintomas, indicadores externos captados pela sensibilidade dos sujeitos (aparências), também escondendo a sua essência, ocultando suas características essenciais. De acordo com Kosik (1995), a realidade não se apresenta aos homens à primeira vista, de forma imediata. "O fenômeno indica a essência e ao mesmo tempo a esconde (...) A essência não se dá imediatamente, é mediada ao fenômeno, e, portanto, se manifesta no fenômeno" (1995, p. 15), mas a regularidade e a evidência dos fenômenos que povoam a vida cotidiana fixam apenas as aparências ou $\mathrm{O}$ mundo $\mathrm{da}$ pseudoconcreticidade, dos fenômenos externos, da prática fetichizada da manipulação, das representações comuns, do mundo dos objetos fixos e suas formas ideologizadas da passividade, da superficialidade e dos falsos problemas.

Um olhar ingênuo sobre os problemas fica nas aparências, na pseudoconcreticidade. Já os verdadeiros problemas exigem 
aprofundamento (ir além da superficialidade), radicalidade (buscar a raiz, a origem), uma visão complexa e de conjunto e uma visão crítica.

De acordo com Saviani (1980), os falsos problemas (pseudoproblemas) identificam-se, nesse sentido, com perguntas simples, indagações a serem respondidas com os "saberes". "Uma questão, em si, não é suficiente para caracterizar o significado da palavra problema. Isto porque uma questão pode comportar (....) resposta já conhecida. Trata-se do problema como não saber" (1980, p. 18). Também o pseudoproblema pode ser identificado com mistério, dificuldade, dúvida; entretanto, se essas situações não necessitam ser resolvidas, deixam de ser problemáticas. $\mathrm{O}$ problema se apresenta como necessidade, necessidade de problematizar o problema.

A problematicidade exige diferenciar o problema complexo do falso problema (pseudoproblema), superando as aparências (pseudoconcreticidade) e captando as necessidades que se impõem objetiva e subjetivamente. Problematizar o problema implica gerar perguntas complexas, um olhar crítico sobre a realidade, onde a suspeita, a dúvida, a curiosidade, a indagação, a questão e a pergunta se tornam pontos de partida do conhecimento. Com base no conceito da "problematização", podemos diferenciar os saberes do conhecimento. Tanto os saberes como o conhecimento podem ter a mesma origem, nos mesmos problemas e a partir das mesmas perguntas; entretanto, os saberes se apresentam como respostas prontas "já dadas", muitas delas organizadas em sistemas de informação ou em conteúdos programáticos dos currículos escolares. Os saberes oferecem respostas para pseudoproblemas, para perguntas simples. Os saberes apresentam respostas elaboradas em outros contextos (geográficos e históricos, espaços e tempos diferentes), as quais são afixadas e/ou sistematizadas (perdem o movimento e a tensão com a pergunta). As respostas acumuladas nos saberes podem ser originadas na crença, na iluminação de autoridade, na revelação (razão mítica), no senso comum (doxa), nas descobertas científicas (episteme) ou nas deduções filosóficas (sofia), mas oferecem respostas prontas, já dadas, desde que exigem a atitude da crença.

Já o conhecimento se refere a respostas novas a serem produzidas. Uma vez esgotada a busca de respostas confiáveis no 
mundo dos saberes sistematizados (bibliotecas, tradições, arquivos informatizados, internet, etc.), tais respostas sofrem o processo da problematização e são submetidas à suspeita e à dúvida. Caso não respondam concretamente ou de forma pertinente aos problemas concretos, dão pé para novas perguntas, neste caso para perguntas complexas revelando necessidades, conflitos, crises para as quais os saberes não têm respostas. $\mathrm{O}$ verdadeiro problema não se identifica com o "não-saber", ele se apresenta como necessidade, obstáculo, dificuldade, dúvida, crise ou conflito para os quais não se tem resposta pronta. Nesse caso, as respostas para os problemas não estão nos saberes. É necessário produzir novas respostas, produzir novos conhecimentos.

Existem problemas, como vimos acima, que se originam na falta de informação; são problemas enquanto não sabemos as respostas. Nesses casos, muitos deles se solucionam com os saberes. É aí que reside a sua importância, porque nos sabres acumulados pela humanidade se tem a capacidade de solução de inúmeros problemas, patrimônio esse que, uma vez disseminado apropriadamente, pode trazer respostas para muitas necessidades da humanidade, saberes sobre as doenças, sobre a natureza, sobre o meio ambiente ou sobre a compreensão da sociedade, seus processos de formação e transformação, por exemplo.

Entretanto, a rigor, esses não seriam os verdadeiros problemas, já que se solucionam com os saberes. Os problemas críticos não têm respostas prontas, exigem o esforço da pesquisa e da produção de novos conhecimentos.

Desdobra-se daí a importância do pesquisador estar capacitado para o trato com saberes sistematizados, a busca nos sistemas de informação, o domínio de teorias que sistematizam esses saberes, mas com a consciência de que esses sistemas apenas informam e oferecem respostas para serem acessadas ou consumidas, não oferecem conhecimentos, como em forma ilusória divulga a denominada sociedade do conhecimento (cf. DUARTE, 2003). Todos os saberes ou respostas já dadas precisam ser problematizados, na medida do possível, recuperando a sua relação com as perguntas que lhes deram origens ou recuperando o potencial de dúvida e curiosidade perante as incertezas implícitas no seu aparente grau de confiabilidade depositado nos pactos e consensos das coletividades acadêmicas e na tradição das disciplinas. A pesquisa educacional precisa desenvolver e superar o conflito entre as respostas já dadas aos problemas, encontradas nas 
redes de informação (revisões de literatura), nas disciplinas e nas teorias, buscando produzir respostas novas, postas pela concreticidade e historicidade desses problemas. No conflito de opostos, poderá se construir uma prática nova que não renuncie aos saberes acumulados e sistematizados, nem negue ou transfira para as elites intelectuais e centros de excelência (internacionais) a capacidade de problematizar, indagar e gerar novas perguntas. Assim como não pode se postergar ou retardar o domínio do instrumental teórico e técnico da pesquisa científica por parte dos profissionais da educação, não se pode tampouco renunciar ao exercício da dúvida e da indagação, à problematização e à criatividade na busca de respostas novas para os problemas complexos derivados da relação do homem com a natureza, das desigualdades sociais, da destruição e degradação ambiental e da sobrevivência do homem e das demais espécies na terra. Os saberes acumulados, certamente, não são suficientes para superar esses novos perigos e desafios. É preciso a ousadia da produção de novos conhecimentos. Pesquisar é preciso.

\subsection{A problemática da Educação Ambiental}

Uma vez postos alguns dos limites e das possibilidades da pesquisa em educação, localizada em espaços restritos da universidade e sob a perspectiva predominante da epistemologia analítica, das temáticas fragmentadas, das ciências aplicadas e das áreas de concentração, é importante apontar alguns desafios para a Pesquisa Ambiental.

Tais desafios se referem à importância da constituição de um novo campo epistemológico que vem se firmando como uma nova perspectiva da produção do conhecimento em educação: a pesquisa em Educação Ambiental (EA).

(...) é possível afirmar que há um campo de pesquisa em EA e que este resulta da confluência de diferentes campos: o ambiental, o educacional e o científico. Há tensões entre eles em torno de objetos em disputa, mas essas promovem embates produtivos e um movimento dinâmico no interior de um campo científico, no qual seus sujeitos se reconhecem e se identificam (KAWASAKI; MATOS, MOTOKANE, 2006, p. 137).

Tal campo em formação está quebrando as amarras da perspectiva analítica de ciência e as metodologias da divisão dos objetos, do controle experimental e das micro-especialidades que geram formas fragmentadas do pensar e do agir. A quebra dessas amarras permite desenvolver alternativas nas perspectivas históricocompreensivas sobre os fenômenos e os problemas, sem separá-los 
e isolá-los de seus ambientes e contextos nem deslocá-los de seus processo evolutivos e das condições da sua produção. Tais perspectivas epistemológicas se afirmam em teorias de conhecimento que concebem a relação dialética entre objetos e sujeitos num processo dinâmico, que produzem respostas e sínteses permanentes para os problemas concretos, que se valem de critérios de validade, atrelados à práxis humana transformadora, e se fundamentam na ontologia da relação do homem com a natureza, da produção social da existência humana e da evolução da humanidade imbricada nas cadeias da inter-relação universal da matéria, da vida e da consciência.

O novo campo científico da EA busca superar os limites restritos da pesquisa educacional localizada nos programas de pósgraduação, acolhendo, nos grupos interinstitucionais de pesquisa, experiências de iniciação científica, ensino de graduação e extensão em projetos ambientais comunitários, integrando saberes com a colaboração de diferentes especialidades e gerando a organização interdisciplinar do conhecimento.

Certamente, a pesquisa em Educação Ambiental está traçando novos rumos para a pesquisa em educação e geral, uma vez que está desenvolvendo novas perspectivas epistemológicas e estreitando as relações entre o meio natural, o socioeconômico e o cultural, entre as teorias científicas e a prática da pesquisa, entre os resultados da pesquisa e a ação política, entre a universidade e a sociedade e revelando as profundas relações entre o homem e a natureza.

\section{Conclusões}

As reflexões sobre os limites e desafios da pesquisa científica na conjuntura dos novos movimentos da produção do conhecimento em educação no Brasil, objeto deste artigo, destacam as dificuldades relacionadas com os conflitos entre a prática e a teoria, os lugares restritos da pesquisa e os limites dos paradigmas científicos dominantes. Destacam, também, os desafios da produção de conhecimentos que ofereçam respostas novas para os problemas gritantes e prementes da atual condição do homem e de suas relações com a natureza, conhecimentos esses que gerem e motivem uma práxis transformadora das atuais condições de degradação biológica e cultural, das estruturas e práticas sociais que reproduzem e aprofundam as desigualdades sociais, a miséria humana, a destruição do patrimônio e dos recursos dos povos sob a racionalidade econômica dominante. 
Novas dinâmicas e novas condições estão sendo conquistadas com as mudanças na organização da pesquisa na universidade e nos programas de pós-graduação e com a ampliação dos lugares da produção do conhecimento, na medida em que se integram projetos de iniciação científica e de extensão, se consolidam os grupos e redes de pesquisa interdisciplinares e se centralizam as linhas de pesquisa em torno dos problemas complexos da educação.

Nesse contexto, a formação de pesquisadores torna-se necessariamente mais complexa. Trata-se de uma formação que precisa equacionar as demandas da dinâmica de acumulação de saberes, cada dia mais abundante, e os critérios de rigor científico, que exigem ponderações e graus de qualificação desses saberes na hora de encontrar respostas válidas para os problemas e necessidades da sua prática social. Novas capacidades precisam ser desenvolvidas para articular o domínio dos saberes sistematizados e o potencial criativo da pesquisa científica e para otimizar os instrumentais técnicos e teóricos necessários para a produção de novas respostas para as necessidades históricas da sociedade na fase atual de profundos processos de transformação.

A formação do pesquisador exige que a universidade amplie as interfaces entre os processos de ensino e os processos de pesquisa num contexto de compromisso social advindo das atividades de extensão com a participação das comunidades, escolas, coletivos, militâncias e movimentos sociais que asseguram o senso de realidade, o potencial de transformação e o compromisso político, sem o quais o conhecimento produzido se esvazia num ritual acadêmico sem nenhuma relevância social e sem significado histórico.

As experiências da pesquisa em Educação Ambiental estão trilhando esses caminhos, assumindo esses desafios e atendendo essas demandas. Dessa forma, está traçando novos rumos para a pesquisa em educação e geral.

\section{Referências bibliográficas}

ANPED. Avaliação e perspectivas na área de Educação, 1982-91, Porto Alegre: CNPq. 1993.

Documento sobre a Pós-graduação na Área. Reunião de avaliação de 1987, Período de referência 85/86. Área: Educação. In ANPED, Boletim, v. 9 , n.4, out-dez 1987. 
BIANCHETI, 1. e MACHADO, A. M. N. (Orgs.) A Bússola do escrever: desafios e estratégias na orientação de dissertações e teses. São Paulo: Cortez; Florianópolis: Ed. UFSC, 2002.

BICUDO, M. A. et al. Pensando a pós-graduação em educação, Piracicaba SP: Ed. Da UNIMEP, 1993.

CAMPOS, M.M. e FÁVERO, O. A pesquisa em Educação no Brasil. Cadernos de Pesquisa. São Paulo (88):5-17, fev. 1994.

CONSELHO NACIONAL DE CIÊNCIA E TECNOLOGIA - CNPq. Grupos de Pesquisa. Questões gerais.

CUNHA, L.A. Pós-graduação em Educação: ponto de inflexão? Cadernos de Pesquisa. São Paulo (77):63-80, maio 1991.

DUARTE, N. Sociedade do conhecimento ou Sociedade das ilusões? Campinas, SP: Autores Associados, 2003.

GATTI, B. A . Formar professores ou pesquisadores no Mestrado em Educação. Boletim Anped, Rio de Janeiro, ANPED, (1):31-34, jan/mar. 1987.

GOUVEIA, A. J., A Pesquisa Educacional no Brasil. Cadernos de Pesquisa, São Paulo, 1(1), 1971.

KAWASAKI C.S.; MATOS, M.S. e MOTOKANE, M.T. o perfil do pesquisador em educação ambiental: elementos para um estudo sobre a constituição de um campo de pesquisa em educação ambiental. Pesquisa em Educação Ambiental, Ribeirão Preto v.1,n.1, p. 111-140, jul/dez. 2006.

KUENZER, A. Z. A pesquisa em Educação no Brasil: algumas considerações. Em Aberto, Brasília, INEP/MEC, (31): 19-23, ago/set, 1986

MORAES, M.C.M. Avaliação na pós-graduação brasileira: novos paradigmas, antigas controvérsias. In: BIANCHETTI, L.; MACHADO, A.M. (Orgs.). A bússola do escrever. São Paulo: Cortez; Florianópolis: UFSC, 2002.

Recuo da teoria: dilemas da pesquisa em educação. Revista Portuguesa de Educação, Braga, v. 14, n. 1, 2001.

ORLANDI, B.L. L. (1983). Apontamentos sobre pesquisa em educação. Falares de Malquerença. Campinas, Cadernos IHCH UNICAMP, n. 8, p. 1-25.

SÁNCHEZ GAMBOA, S. As condições da produção científica em educação: do modelo de áreas de concentração aos desafios das linhas de pesquisa. Educação 
Temática Digital, ETD, Faculdade de Educação, UNICAMP. Vol. 4, N.2 Jul. de 2003. p. $78-83$.

. Dinâmicas e conflitos na produção do conhecimento: o caso da Pósgraduação em Educação da Unicamp. Educação Temática Digital ETD, Vol. 8 n. 1 dez de 2006.

SAVIANI, D. Pedagogia histórico-crítica. São Paulo: Cortez/AA, 1991.

A pós-graduação em educação no Brasil: pensando o problema da orientação. In: BIANCHETI, 1. MACHADO, A.M.N. (Orgs.). A Bússola do escrever: desafios e estratégias na orientação de dissertações e teses. São Paulo: Cortez, Florianópolis: Ed. UFSC, 2002, p. 135-163.

- Concepção de mestrado centrada na idéia de monografia de base. Educação Brasileira, 13(27): 1991, p. 159-168.

SCHIMIED-KOWARZIK. Pedagogia dialética. São Paulo: Brasiliense, 1988.

SEVERINO, A.J. Consolidação dos cursos de pós-graduação em Educação: condições epistemológicas, políticas e institucionais. In: SEVERINO, A.J.; FAZENDA, I.C.A. (Orgs.). Conhecimento Pesquisa e Educação. Campinas: Papirus, 2001, p. 51-65.

; FAZENDA, I.C.A. (Orgs.). Conhecimento Pesquisa e Educação. Campinas SP: Papirus, 2001.

SILVA, R.C. O fórum paulista de pós-graduação em educação: uma experiência desafiante. In: SEVERINO, A . J. ; FAZENDA I. C. A. (Orgs.). Conhecimento Pesquisa e Educação. Campinas: Papirus, 2001. p. 19-35.

WARDE, M. O papel da pesquisa na pós-graduação em educação. Cadernos de Pesquisa. São Paulo (73):67-75, Maio 1990. 